\title{
Vangelis Vitalis
}

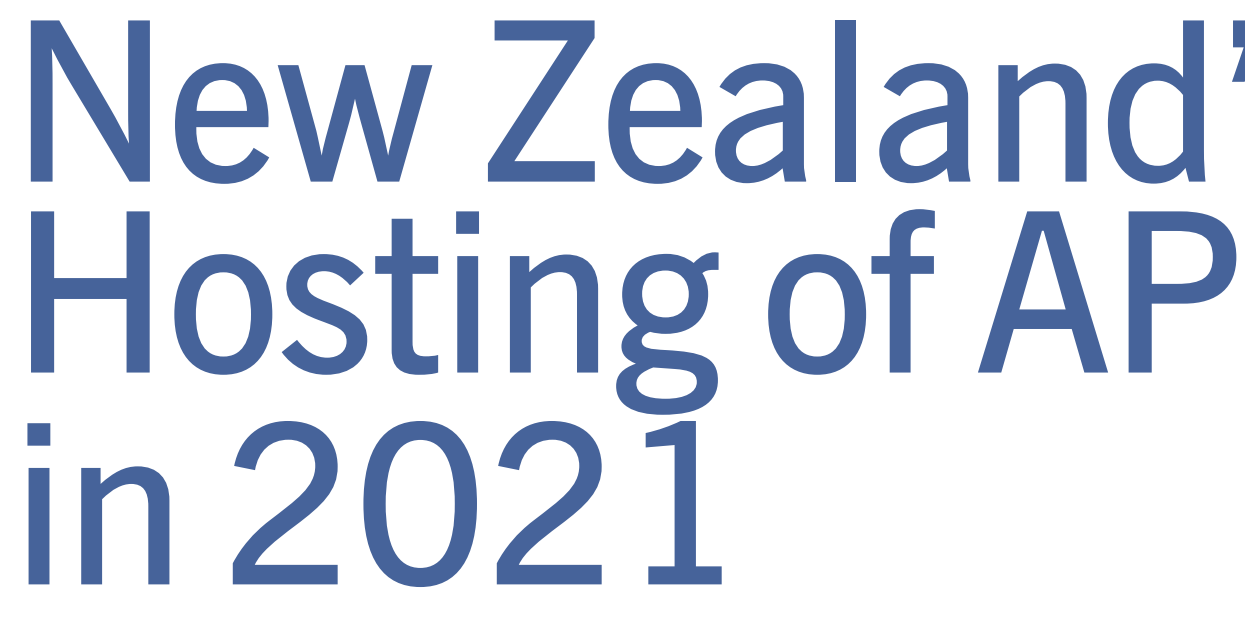

\section{Abstract}

Hosting APEC in 2021 is a unique and timely opportunity for New Zealand to take responsibility for providing regional leadership that can advance and sustain APEC as an institution, including through its development of trade and economic policies that will support the region's economic recovery from the effects of Covid-19. This article reviews why APEC matters to New Zealand and the international context which will influence New Zealand's APEC host year. It outlines how New Zealand will approach its virtual hosting of APEC 2021, and the key themes which will inform our priorities.

Keywords APEC, international organisations, regional economic integration
$\mathrm{T}$ he Greek general Thucydides, writing 2,500 years ago, is supposed to have said that 'turbulence is a stern teacher'. Recent years have certainly been that for us as we have navigated an increasingly complex and challenging international economic environment. Covid-19 has further underlined the essential fragility both of globalisation in general, and of the rules-based international trading system in particular. At the heart of that system for the past quarter of a century has been APEC - the Asia-Pacific home for a set of regional norms and morés that more than most institutions has shaped and informed the evolution of our regional
Vangelis Vitalis is Deputy Secretary, Trade and Economic at the Ministry of Foreign Affairs and Trade. He is also the APEC Senior Officials' Meeting chair for New Zealand's APEC 2021 host year. His previous roles include: the chief negotiator who concluded the Comprehensive and Progressive Agreement for TransPacific Partnership (CPTPP) and the ASEAN-Australia-New Zealand Free Trade Agreement; ambassador to the EU; and, more recently, New Zealand's permanent representative to the WTO.

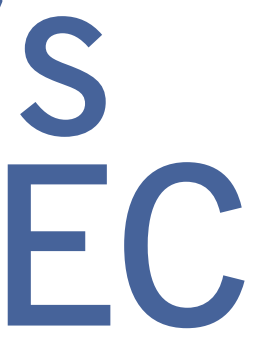

economic architecture and underpinned our prosperity.

The last time New Zealand hosted APEC was in 1999. It was a challenging year: except with Australia, we had no formal regional or bilateral trade architecture and had yet to venture into any free trade agreement negotiations; the $\mathrm{Y} 2 \mathrm{~K}$ bug was a serious preoccupation; the region was grappling with the aftermath of a crippling Asian financial crisis; the Cold War was a recent memory; and the World Trade Organization was in a parlous state heading into the Seattle ministerial conference. It all suggested that Francis Fukuyama's declaration of 'the end of history' a decade before our host year was naïve at best, hubristic at worst.

In 2021 New Zealand will host APEC again. And, once again, the context is challenging, not least as the health, social and economic impacts of the Covid-19 pandemic continue to unfold. Despite the challenges, hosting APEC is a unique and timely opportunity for New Zealand to take responsibility for providing regional leadership that can advance and sustain APEC as an institution, including through its development of trade and economic policies that will support the region's economic recovery.

Here I review why APEC matters to New Zealand, especially in such turbulent times. I frame this against an international 
context which will influence New Zealand's APEC host year. I then outline how New Zealand will approach its virtual hosting of APEC 2021, and the key issues which will inform our priorities.

\section{APEC and New Zealand}

APEC represents a crucial anchor point for New Zealand in a dynamic and rapidly evolving region. It is also a way to mitigate the risks posed by the 'Kindleberger Trap'. This is the situation described by Charles Kindleberger, one of the architects of the Marshall Plan. He argued that the disastrous decade of the 1930s was enabled by the failure of countries (large and small) to invest in and sustain key global public goods, such as the League of Nations. It has been suggested that this is the new 'trap' confronting us internationally: whether countries will support and invest in our existing global and regional public goods to sustain the rules-based system. APEC is a good example of a public good that frames and sustains the international trading system, not least through its cooperative and consensus-based processes, which drives collaboration, innovation and shared outcomes. We now have an opportunity, as a small economy that depends on a sustainable rules-based system, to make our contribution in support of APEC, and in this way avoid Kindleberger's trap.

There are also good practical reasons to 'lean in' on APEC. APEC members enjoy a successful history of pursuing economic integration, which has driven the region's prosperity. APEC's design - centred on consensus-based commitments, voluntary action and capacity building - has been key to this success. Its non-binding and collaborative method of engagement has enabled the institution to serve as an incubator of ideas. It was APEC that devised the first set of environmental goods in the 1990s as part of the 'early voluntary sectoral liberalisation' process, and it was APEC - in Russia's 2012 host year - which established the first internationally agreed set of environmental goods on which member economies agreed to reduce or eliminate tariffs.

APEC has thus proven to be a flexible and adaptable forum for sharing experiences, engaging the private sector,
Since APEC was founded in 1989, its collective GDP per capita has doubled and approximately a billion people have been lifted out of poverty across the region.

developing best practices, and building common attitudes and norms around constructive trade, microeconomic and macroeconomic policies. The APEC process of exchanging good ideas and instilling best practice has already yielded important gains across the region: it is, for instance, radically faster for an entrepreneur today to establish a business or obtain a construction permit in the APEC region than it was a decade ago. And that same businessperson deals with less red tape and enjoys a more level playing field thanks to pro-competition policies. In this way, APEC has made significant contributions to New Zealand's prosperity by coordinating actions which helped the Asia-Pacific become the most economically dynamic region in the world.

APEC's activities also have a record of building over time into 'hard rules' (i.e. legally enforceable trade rules). To give you an example, I do not believe that we could have concluded the 'hard rules' contained in the ASEAN-Australia-New Zealand Free Trade Agreement without the many years of patient work undertaken in APEC on issues like customs procedures, trade facilitation mechanisms, competition policy and so on. The norms developed through sharing information and best practice in APEC built confidence and familiarity. These fed directly into the outcomes that were secured for New Zealand in 2008 with ASEAN (one of our most important trading partners) and subsequently into the Comprehensive and Progressive Agreement for Trans-Pacific
Partnership (CPTPP) outcomes. Practical outcomes like self-certification for rules of origin secured with our close partner Malaysia - which significantly reduce transaction and financial costs for both of our countries' exporters - would simply not have been possible without the close collaboration of our respective customs officials working together for years in a range of APEC forums. Put simply, the familiarity and trust that evolved between officials in APEC processes built confidence and provided the crucial building blocks of norms and best practice that shaped the range of subsequent 'hard' trade rules found in our regional and bilateral trade agreements.

Since APEC was founded in 1989, its collective GDP per capita has doubled and approximately a billion people have been lifted out of poverty across the region. New Zealand exporters have benefited not only from being part of this growing region and its rapidly expanding middle class with a taste for the high-quality and safe goods we produce, but also from the average tariffs in the APEC region falling from 17\% at its founding to $5 \%$ today (although average agricultural tariffs remain more than twice as high as non-agricultural tariffs). This was achieved through what we might call the 'APEC effect', whereby the policies and thinking of APEC members shifted towards placing value on voluntary reform and greater integration as a driver of economic prosperity and well-being. It is, therefore, not at all surprising that New Zealand's trading relationships have come to be dominated by APEC markets, including as the home of eight of our top ten export destinations.

This collective regional approach, in which the gradual opening of economies is seen as a means to benefit all, also includes a wide-ranging structural reform agenda. This is a vital component in our broader vision of a region that is prosperous and economically vibrant. APEC works to foster transparency, competition and better-functioning markets in the AsiaPacific through sharing information and best practice on regulatory reform, improving public sector and corporate governance, and strengthening legal systems. Crucially too, the APEC Business Travel Card provides our exporters with 
streamlined access to APEC economies. This is another concrete deliverable from the 'APEC effect'. In practical terms, this has all meant that it has become significantly cheaper, faster and easier to do business across the APEC region.

APEC's work to advance integration by reducing barriers to trade and creating efficient markets is central to New Zealand's economic well-being and the jobs that are sustained by our export sector. Our links with the Asia-Pacific are essential to our prosperity. They will be a key plank both in New Zealand's economic recovery from the Covid-19 pandemic, and in our future resilience.

\section{International context for APEC 2021}

As I noted at the outset, New Zealand will host APEC during difficult times. Most obviously, the global economic impacts of Covid-19 are likely to get worse before they get better.

The OECD forecasts that Covid-19 will trigger a $4.5 \%$ decline in global growth this year, with a resultant sharp increase in unemployment. It found that global trade collapsed in the first half of 2020, falling by over $15 \%$, and remains weak. At the same time, there is a risk that the surge in restrictive trade measures being put in place around the world in response to the pandemic will herald a new era of protectionism.

But even before the arrival of Covid-19, the broader international context was troubling for a small player like New Zealand. We have seen rising scepticism around the ability of international rules and organisations to cope with a range of trends, including increasingly assertive competition among large powers, unilateral trade actions, fraying political consensus on liberal economic norms, and growing environmental pressures.

APEC has a critical role to play across these issues. It has been at the heart of regional economic diplomacy for decades, including previous periods of political and economic turbulence. It is imperative that APEC now finds a way to sustain and build on the progress it has made. There are two ways we can do this next year, building on the good work already undertaken by Malaysia as APEC host this year.
The nature of APEC, based on the principles of voluntary action and consensus, means that ultimately what can be achieved in 2021 will depend on the willingness of each member economy to promote cooperation rather than competition.

First, at a time when major powers are not actively defending global public goods such as the rules-based trading system, smaller countries need to step in to sustain them. In this context, hosting APEC provides the opportunity for us to convene key international actors and remind each other that we must not lose sight of the values which have led to the Asia-Pacific being the most dynamic and fastestgrowing region in the world. APEC should, therefore, be a space for constructive engagement and cooperation on regional and global norms, with a view to rebuilding confidence in, and support for, the rulesbased international system.

Second, our role as host next year is an opportunity for us to support Asia-Pacific economies in sharing knowledge and experience of policies that will support a rapid recovery from a once-in-a-generation economic crisis. We need to design and adopt policies that enable business with open, competitive and predictable corporate environments that stimulate productivity, jobs and incomes. APEC is where best practice to respond to the economic impacts of Covid-19 can be debated, shared and coordinated across the region. APEC's focus, then, is necessarily both macro- and microeconomic. On the trade policy front, too, recovery strategies will need to avoid the kinds of protectionism that history has shown will leave everyone worse off. In this way, the APEC principle of open trade and investment remains a key element in our shared strategy to stave off the worst of the pandemic's economic impact.

\section{New Zealand's APEC host year in 2021}

In a typical year APEC meetings would see prime ministers, presidents and other leaders rubbing shoulders as they worked to advance their shared trade and economic interests, while CEOs from around the region would come together to make deals to expand their commercial opportunities. Unfortunately, during a global pandemic these kinds of close and personal interactions are simply not possible, at least not in the near future. New Zealand is therefore hosting APEC 2021 in a virtual manner.

In hosting over 300 APEC meetings online, in what will arguably be the largest digital diplomacy event ever attempted, New Zealand will make the most of the opportunities provided by the virtual format to underpin APEC's important work. We will be innovative and creative in delivering a tightly focused programme of work that can make a real impact on the issues that matter most.

As APEC host, New Zealand's first responsibility will be to steward the organisation through a tumultuous period defined by a health crisis and deep economic shocks across the region. Much of New Zealand's role as host will necessarily centre on coordinating APEC's response to this crisis and guiding its future strategic direction in light of the pandemic's impact. As host, New Zealand will also place special emphasis on issues that will be key to sustained economic recovery.

Five significant themes will inform our host year. First, this year APEC is expected to replace the expiring Bogor Goals ${ }^{1}$ with a new mission statement for APEC. In 2021 
APEC will translate this new vision into a detailed plan of action to guide APEC's agenda in the decades to come. As host, a core role for New Zealand will therefore be to facilitate agreement on this 20-plus year agenda. Given the state of the international economy, this is a significant responsibility. It is also an opportunity for New Zealand to help design a work plan for APEC which galvanises its membership, responds to the challenges of Covid-19, and aligns as far as possible with our core economic values and interests.

Second, the APEC region is expected to lose around US $\$ 3$ trillion in economic output due to Covid-19. In response, APEC must promote economic policies that will help the region resume its growth path. APEC members need to continue to find ways to deepen integration, make it easier to do business across the region, and reduce barriers to trade. New initiatives will also be needed to make our economies more resilient. We will have good ideas to share, and also much to learn from the experiences of other economies.

Third, over recent decades rising inequality has been a global trend, with the top $1 \%$ of earners capturing twice as much of the total income growth as the bottom 50\%. APEC can help its members find ways to more fairly spread the benefits of international connectivity across society, and to ensure that inequality is not exacerbated by the Covid-19 crisis. Economic recovery should not leave behind critical economic actors such as small and medium-sized businesses, women, the regions, and the Asia-Pacific's indigenous populations. This is not only the right thing to do as a matter of principle; it is also essential to building a shared, inclusive vision for our economic future.

Fourth, APEC economies represent around $40 \%$ of the global population, consume more than half of the world's energy, and produce around $60 \%$ of global greenhouse gas emissions. The region's economic recovery and future growth must, therefore, be sustainable for the planet. This means finding ways to tackle environmentally harmful subsidies which can distort markets in a range of resources, from fish to fossil fuels. It also means considering what best practice policies look like to encourage emerging sectors in green industries, renewable energy and environmental goods and services, and removing barriers to their uptake. A sustainable economy will be more resilient to future shocks and better placed to undergo transformation in response to climate change.

Finally, the explosion of new technologies over the past 30 years has resulted in more than 20 billion devices now being connected to the internet, transmitting 75,000 gigabytes of data every second. Digitalisation now touches on almost all aspects of economic activity. The changes in consumer and workplace behaviours seen as a result of Covid-19 have also highlighted how essential digital technologies are for work, commerce and the delivery of public services. A digitally enabled economy, with broad participation across our people and businesses, will be better placed to recover and thrive.

Strengthening the digital economy requires grappling with a wide range of complex issues that APEC is well placed to help with. Rules around the movement and storage of data need to spur innovation and cross-border interoperability while also preserving trust and confidence through appropriate privacy and security safeguards. The ongoing debate regarding the WTO moratorium on customs duties on electronic transmissions remains a matter of keen interest to many APEC partners. Issues around artificial intelligence are now a part of the emerging agenda, as well as how digital tools should be used to make it easier to export goods and services without being manipulated to create barriers to trade. Regulatory frameworks must be designed to promote investment in infrastructure and ensure robust competition. And many emerging technologies hold exciting potential, but need to be developed responsibly to avoid unintended consequences. APEC has a role to play in convening and sharing best practice around all of these issues, and has an opportunity to shape the emerging norms and mores in this area as well.

\section{Conclusion}

At a time when the international system is under intense pressure, APEC should seize the opportunity to demonstrate that collective international action not only works, but is in our shared interests. This is the challenge not only for New Zealand as APEC host in 2021, but for the entire APEC membership.

Given the economic pressures faced by member economies as a result of Covid-19, this is no simple task. The nature of APEC, based on the principles of voluntary action and consensus, means that ultimately what can be achieved in 2021 will depend on the willingness of each member economy to promote cooperation rather than competition. As host, New Zealand will do all it can to help APEC live up to the ideals on which it was founded - that by working together to encourage free and open trade and investment the region will come closer to achieving its full potential, making us all more prosperous and secure.

One way to frame our approach to hosting APEC next year is with reference to the Aristotelian concept of knowledge. This distinguishes between three types of knowledge: episteme (theoretical knowledge), techne (technical knowledge) and phronesis (practical wisdom). For Aristotle, these three forms of knowledge together were at the heart of eudaimonia, the state of ethical and political well-being. New Zealand has traditionally deployed all three of these forms of knowledge in support of APEC. Going forward, it will be the application of phronesis in particular that may best help New Zealand to effectively host this critically important global public good in 2021.

\footnotetext{
The Bogor Goals, agreed by APEC leaders in 1994, include a commitment to achieve free and open trade and investment in the Asia-Pacific by 2010 for industrialised economies and by 2020 for developing economies. APEC members agreed to pursue this goal by further reducing barriers to trade and investment and by promoting the free flow of goods, services and capital.
} 